\title{
APROVEITAMENTO DA GLICERINA EM UMA CÉLULA A COMBUSTÍVEL MICROBIOLÓGICA: INFLUÊNCIA DO TEMPO DE RETENÇÃO HIDRÁULICO E A IDADE DO LODO NO DESEMPENHO ELETROQUÍMICO
}

\author{
AMANDA QUEIROZ GUIMARÃES ${ }^{1}$, JOSÉ J. LINARES ${ }^{1}$ \\ ${ }^{1}$ Universidade de Brasília, Instituto de Química, Divisão de Química Tecnológica \\ E-mail para contato: joselinares@unb.br
}

\begin{abstract}
RESUMO - Este trabalho apresenta os resultados obtidos do aproveitamento do glicerol em uma célula a combustível microbiológica. Em particular, neste trabalho foi analisada a influência do tempo de retenção hidráulico do sistema, sendo observado um valor ótimo de desempenho para um tempo de 10 dias com uma voltagem de $18 \mathrm{mV}$ (circuito fechado por uma resistência de $100 \Omega$ ) e uma remoção de DQO do $90 \%$. Valores mais elevados conduzem a menores taxas de remoção de matéria orgânica, enquanto valores inferiores limitam o desempenho eletroquímico. Da mesma forma, foi analisada a influência do tempo de retenção hidráulico, sendo observado um valor ótimo de 20 dias de forma a maximizar o desempenho eletroquímico do sistema e manter uma ótima capacidade de remoção de matéria orgânica (até 95\%). Idades do lodo superiores parecem desfavorecer o crescimento dos microrganismos geradores de eletricidade.
\end{abstract}

\section{INTRODUÇÃO}

O crescimento significativo da indústria de biodiesel no Brasil tem gerado um importante excedente de glicerina subproduto do processo de produção de biodiesel (Vasconcelos, 2012). Tal situação demanda de alternativas às clássicas das indústrias alimentícias, cosméticas e farmacêuticas (Motta et al., 2009), incapazes de gerenciar as grandes quantidades geradas. Entre as alternativas sugeridas para valorizar ao biodiesel produzido encontra-se os sistemas microbiológicos, através de, principalmente, a via fermentativa (Yazdani e Gonzalez, 2007), aproveitando a biodegradabilidade do glicerol. Como alternativa a este processo, tem sido proposto recentemente o uso deste como fonte de matéria orgânica para uma biocélula a combustível. Resultados interessantes têm sido apresentados por diferentes grupos de pesquisa (Reiche e Kirkwood, 2012; Nimje et al., 2011; Gomes et al., 2011) para glicerol puro, e para glicerol bruto procedente do processo de produção de biodiesel (Dantas et al., 2013; Feng et al., 2011).

Diferentes tipos de sistemas e configurações têm sido propostas, sendo a mais convencional a de célula em forma de $\mathrm{H}$. Nela, o sistema está formado por dois compartimentos, anolito e catolito conectados através de uma ponte onde pode ser colocada uma membrana de troca iônica ou uma ponte salina (Logan, 2009). Da mesma forma, diferentes tipos de materiais eletródicos têm sido objeto 


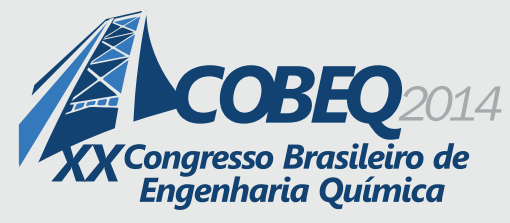

19 a 22 de outubro de 2014
Florianópolis/SC

de estudo, sendo os mais comuns aqueles de natureza carbonácea, na forma de barras de grafite, espumas ou escovas. Também têm sido amplamente utilizados tecidos ou feltros de carbono como material anódico. O intuito é fornecer superfície onde os microrganismos possam fixar-se no caso da formação de biofilmes e ocorrer a transferência de elétrons (Kumar et al., 2013).

Um estudo prévio realizado por este grupo de pesquisa tem demonstrado resultados satisfatórios do desempenho bioeletroquímico do sistema, produzindo, por um lado, eletricidade, e por outro, decrescendo a quantidade de matéria orgânica no efluente da célula (Queiroz Guimarães e Linares, 2014). Nesse primeiro estudo, foi analisada a influência da concentração de glicerol alimentado ao reator eletroquímico, sendo obtido um ótimo de concentração de $1080 \mathrm{mg} \mathrm{L}^{-1}$. Na linha do trabalho anterior, o objetivo deste é estudar a influência de duas variáveis de operação importantes neste tipo de sistemas: o tempo de retenção hidráulico (TRH) e a idade do lodo (IL) (Tchobanoglous et al., 2003).

\section{MATERIAL E MÉTODOS}

O sistema experimental empregado neste trabalho consiste em uma célula de PVC com forma de $\mathrm{H}$, onde se encontrarão os dois meios usados. $\mathrm{O}$ anolito contém o meio de crescimento dos microrganismos geradores de eletricidade, e o catolito é composto essencialmente por um meio tampão de fosfato onde ocorrerá o processo de redução de oxigênio. O volume dos dois compartimentos é de aproximadamente $250 \mathrm{~mL}$. No processo de arranque do sistema, misturam-se $100 \mathrm{~mL}$ de lodo procedente do reator biológico da Estação de Tratamento de Esgoto "Asa Norte" da empresa de gerenciamento de águas do Distrito Federal (CAESB) com $150 \mathrm{~mL}$ da solução alimento cuja composição se especifica na Tabela 1. Prévio à preparação da célula, o lodo foi mantido durante 5 dias dentro do recipiente coletor para favorecer o crescimento de bactérias anaeróbias.

Tabela 1 - Composição da água residual sintética usada no ânodo e do tampão fosfato do cátodo

\begin{tabular}{|c|c|c|c|}
\hline \multicolumn{2}{|c|}{ Composição da água residual } & \multicolumn{2}{|c|}{ Phosphate buffer solution } \\
\hline Composto & $\begin{array}{c}\text { Concentração / } \\
\text { mg.L } L^{-1}\end{array}$ & Composto & $\begin{array}{c}\text { Concentração / } \\
\text { g.L }\end{array}$ \\
\hline Glycerol & 320,0 & $\mathrm{Na}_{2} \mathrm{HPO}_{4}$ & 2,75 \\
\hline$\left(\mathrm{NH}_{4}\right)_{2} \mathrm{SO}_{4}$ & 74,2 & $\mathrm{NaH}_{2} \mathrm{PO}_{4}$ & 3,67 \\
\hline $\mathrm{KH}_{2} \mathrm{PO}_{4}$ & 44,5 & & \\
\hline $\mathrm{NaHCO}_{3}$ & 111,0 & & \\
\hline $\mathrm{MgCl}_{2}$ & 37,1 & & \\
\hline $\mathrm{CaCl}_{2}$ & 30,7 & & \\
\hline$\left(\mathrm{NH}_{4}\right)_{2} \mathrm{Fe}\left(\mathrm{SO}_{4}\right)_{2}$ & 3,1 & & \\
\hline
\end{tabular}

Como material eletródico no ânodo foi utilizado uma barra de grafite de área superficial 27,75 $\mathrm{cm}^{2}$. No cátodo, foi utilizado igualmente uma barra de grafite de similares dimensões, sobre a que se depositou uma camada de catalisador $\left(0,5 \mathrm{mg} \mathrm{cm}^{-2}\right.$ de Pt, 20\% Pt/C, BASF Fuel Cells) contendo um $10 \%$ de Nafion $^{\circledR}$ com ajuda de um pincel, prévia preparação de uma tinta viscosa, sendo usado 2- 


\section{9 a 22 de outubro de 2014 \\ Florianópolis/SC}

propanol como solvente. A separação entre os dois compartimento foi realizada com ajuda de uma membrana de troca catiônica, Nafion ${ }^{\circledR} 117(178 \mu \mathrm{m})$. As conexões elétricas foram realizadas mediante fiação de cobre, a qual foi isolada na área de contato com os dois meios eletrolíticos. Uma representação esquemática do sistema é apresentada na Figura 1.

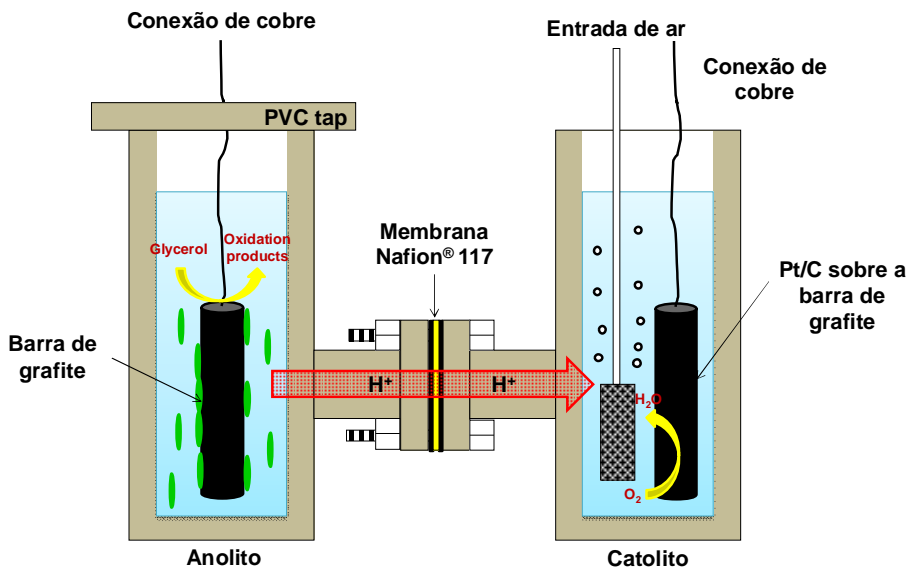

Figura 1. Esquema da célula a combustível microbiológica

O fornecimento de ar ao cátodo foi realizado com ajuda de um compressor de aquário. A alimentação ao sistema se realizou de forma diária. A mesma quantidade de solução do anolito é retirada, sendo avaliada a Demanda Química de Oxigênio (DQO) segundo procedimento padronizado (ASTM D1292). As medidas eletroquímicas foram realizadas com ajuda de um potenciostato/galvanostato $\mu$ AUTOLAB III (Metrohm Pensalab) no final de cada ciclo operativo antes da alimentação. Para isto, espera-se a que o sistema, previamente, haja atingido uma voltagem constante em circuito fechado com resistência de $100 \Omega$, condição na que se realiza o processo de aclimatação, tal como descrito por Queiroz Guimarães e Linares (2014). As curvas de polarização foram realizadas na forma de voltametria de varredura linear desde a voltagem de circuito aberto até zero volt.

\section{RESULTADOS E DICUSSÃO}

A Figura 1 apresenta a variação da voltagem e da demanda química de oxigênio no efluente do sistema para os diferentes tempos de retenção hidráulica usados no sistema. Como pode ser observado, o desempenho eletroquímico do sistema se incrementa com o tempo de retenção hidráulico até o valor limite de 10 dias, correspondente a um volume de purga de $20 \mathrm{~mL}$. No caso da demanda química de oxigênio, pode ser observado um leve incremento com a redução do TRH até o valor limite de 10 dias (aproximadamente 90\% de remoção), a partir do qual se observa uma subida considerável. Estes resultados revelam a existência de um TRH ótimo, o suficientemente elevado para que os microrganismos possam degradar a matéria orgânica e utilizá-la para crescimento próprio (anabolismo) e para a geração de energia elétrica (catabolismo) sem chegar a situações de ausência de substrato. Por outro lado, um tempo de retenção hidráulico excessivamente baixo reduz o desempenho eletroquímico e incrementa a DQO na saída da célula, devido ao insuficiente tempo dado aos 
microrganismos para seu desenvolvimento e a conseguinte eletroxidação do glicerol (Sharwa et al., 2010).

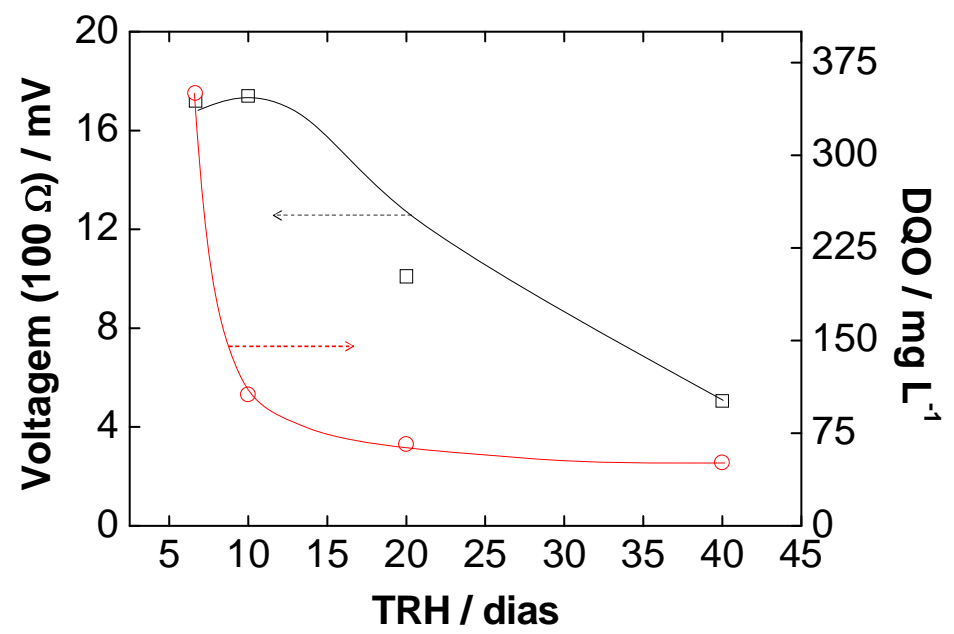

Figura 2. Variação da voltagem e a DQO para os diferentes tempos de retenção hidráulica (DQO ${ }_{\text {afluente }}$ $\left.=1250 \mathrm{mg} \mathrm{L}^{-1}\right)$

A Figura 3 apresenta as curvas de polarização e de potência para os diferentes TRH, mostrando a capacidade de produção de energia elétrica do sistema. Como pode ser observado, o desempenho elétrico melhora com o tempo de retenção hidráulico, sendo refletido isto nos máximos de potência, os quais se incrementam até o valor limite de 10 dias. A partir daí, é observada uma queda tanto no máximo de potência quanto na voltagem de circuito aberto, revelando que os microrganismos produtores de eletricidade não se encontram nas condições ótimas. No caso da operação com um tempo de retenção hidráulica de 10 dias, é possível obter um máximo de potencia de $12 \mathrm{~mW} \mathrm{~m}^{-2}$, reafirmando as condições ótimas de operação anteriormente observadas na Figura 2.

Uma vez estabelecido o TRH mais adequado, a seguinte etapa consistiu no estudo da influência da idade do lodo. Por esta se entende o tempo que é deixado este dentro do reator bioeletroquímico. Nos estudos do TRH, ambos os parâmetros foram mantidos iguais, previa agitação do anolito antes da purga do efluente. Geralmente nos processos de tratamento de esgoto, para um funcionamento ótimo do sistema, este parâmetro é maior que o TRH. Se o valor for excessivamente curto, produzir-se-á uma lavagem de microrganismos, reduzindo de forma significativa a eficiência do processo. Se o tempo for longo demais, e particularmente para este tipo de sistemas bioeletroquímicos, pode ser favorecido o crescimento de outros tipos de microrganismos diferentes daqueles geradores de energia elétrica, os quais entrarão em competição com estes pelo substrato. Além disso, pode ser gerada uma quantidade excessiva de lodo, sendo dificultada a operação de biocélula a combustível.

Na Figura 4 se mostra a influência da idade do lodo na voltagem da célula e na DQO do efluente extraído do sistema diariamente. É importante mencionar que o limite inferior considerado da IL coincidirá com o TRH ótimo, sendo estudados valores acima deste. O procedimento operativo se 
esquematiza na Tabela 2.

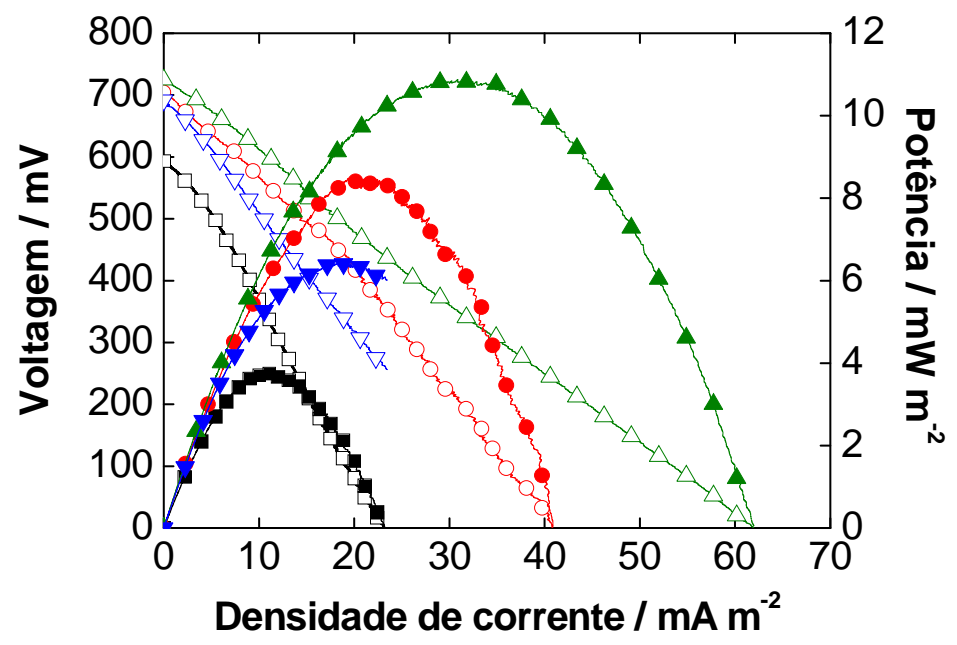

Figura 3. Curvas de polarização para os diferentes tempos de retenção hidráulicos ( $\square \square: 40$ dias; $\bigcirc: 20$ dias; $\Delta \triangle: 10$ dias; $\nabla \nabla: 5$ dias). Os símbolos ocos representam a voltagem da célula, enquanto os símbolos recheados representam a potência.

Tabela 2 - Esquema operativo para a análise da influência da idade do lodo (E: retirada apenas do efluente sem lodo; E+L: retirada de efluente junto com lodo, purga de $20 \mathrm{~mL}$ )

\begin{tabular}{|c|c|c|c|c|c|c|c|c|c|}
\hline \multicolumn{9}{|c|}{ Dias } \\
\hline IL / dias & 1 & 2 & 3 & 4 & 5 & 6 & 7 & 8 & 9 \\
\hline 10 & E+L & E+L & E+L & E+L & E+L & E+L & E+L & E+L & E+L \\
\hline 20 & E+L & E & E+L & E & E+L & E & E+L & E & E+L \\
\hline 30 & E+L & E & E & E+L & E+L & E & E & E+L & E \\
\hline 40 & E+L & E & E & E & E+L & E & E & E & E+L \\
\hline
\end{tabular}

Como pode ser observado, existe um valor ótimo da idade do lodo em 20 dias, onde, por um lado, maximiza-se a produção de energia elétrica, junto com uma maior capacidade de degradação do glicerol substrato (até 95\%). Valores acima deste ótimo reduzem o desempenho eletroquímico do sistema, apesar da redução em maior medida da DQO. Um possível motivo deste comportamento é que, nessas condições, não é favorecido o desenvolvimento de microrganismos produtores de energia elétrica, frente a outros tipos que, muito provavelmente, favorecerão as fermentativas.

Na Figura 5 são apresentadas as curvas de polarização e de potência para as diferentes idades do lodo. Como pode ser observado, o melhor desempenho eletroquímico se obtém para uma IL de 20 dias, confirmando os resultados previamente obtidos nas medidas feitas em circuito fechado (resistência de $100 \Omega$ ). Nestas condições é possível maximizar a potência extraída da biocélula. Um incremento da idade do lodo causa uma queda na voltagem de circuito aberto além de uma redução no máximo de potência. Como mencionado anteriormente, uma idade do lodo prolongada não favorece o 
desenvolvimento satisfatório dos microrganismos produtores de energia elétrica, refletindo-se isto em uma queda do desempenho eletroquímico.

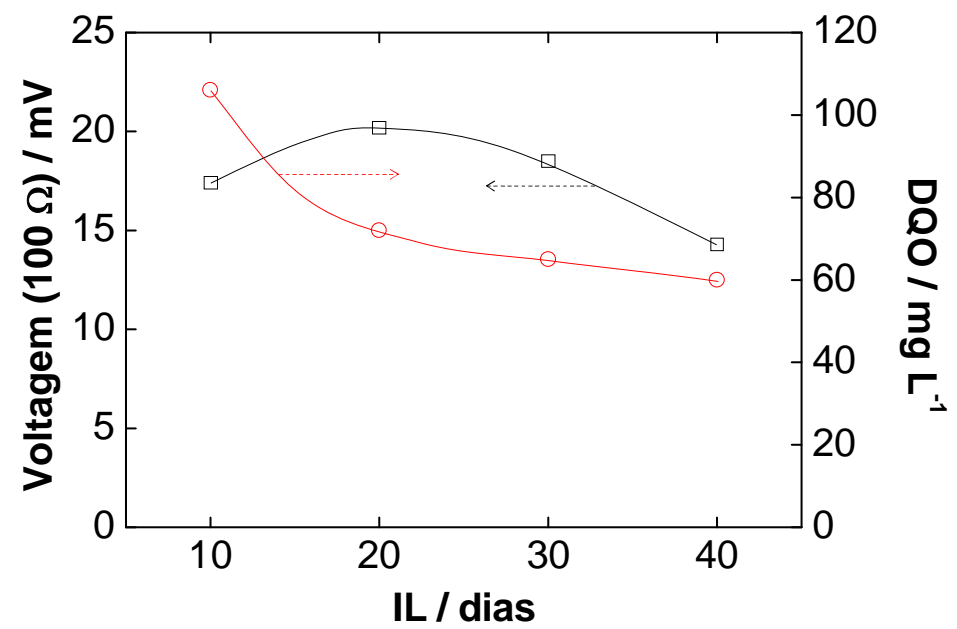

Figura 4. Influência da idade do lodo sobre a voltagem e a DQO para as diferentes idade do lodo $\left(\mathrm{DQO}_{\text {afluente }}=1250 \mathrm{mg} \mathrm{L}^{-1}\right)$

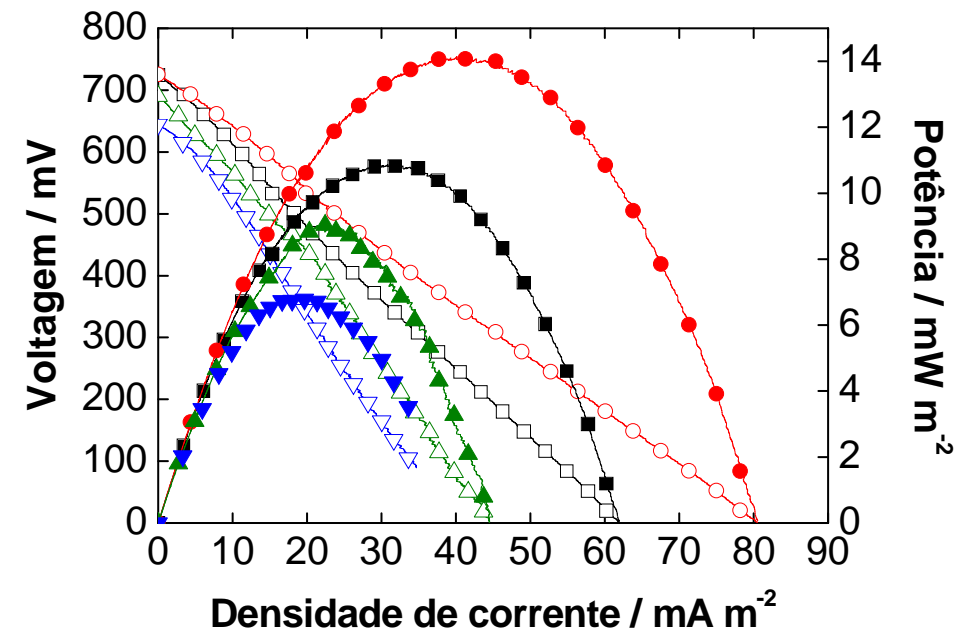

Figura 5. Curvas de polarização para as diferentes idades do lodo ( $\square \square$ : 10 dias; $\bigcirc \bigcirc: 20$ dias; $\Delta \triangle$ : 30 dias; $\nabla \nabla: 40$ dias). Os símbolos ocos representam a voltagem da célula, enquanto os símbolos recheados representam a potência. 


\section{9 a 22 de outubro de 2014 \\ Florianópolis/SC}

\section{CONCLUSÕES}

O presente trabalho demonstra a importância da seleção de condições de operação adequadas para maximizar o desempenho eletroquímico de uma célula a combustível microbiológica alimentada com glicerol, em particular o tempo de retenção hidráulico e a idade do lodo. Através dos valores ótimos, 10 dias para o primeiro parâmetro, e 20 dias para o segundo, é possível maximizar a produção de eletricidade do sistema, o que se reflete na maior voltagem em circuito fechado (20 mV para uma resistência externa de $100 \Omega$ ), e uma máximo de potência em curva de polarização de $14 \mathrm{~mW} \mathrm{~cm}^{-2}$. Além disto, o sistema mantém uma elevada capacidade de remoção de DQO, atingindo um valor de quase $90 \%$.

\section{AGRADECIMENTOS}

Os autores agradecem à companhia distrital de gerenciamento de águas do Distrito Federal, CAESB, pela gentil doação do lodo procedente do reator biológico do tratamento secundário da ETE Asa Norte.

\section{REFERENCIAS}

DANTAS, P.V.; PERES, S.; CAMPOS-TAKAKI, G.M.; LA ROTTA, C.E. Utilization of Raw Glycerol for Pyocyanin Production from Pseudomonas Aeruginosa in Half-Microbial Fuel Cells: Evaluation of Two Electrochemical Approaches. J. Electrochem. Soc., v. 160, p. G142-G148, 2013.

FENG, Y; YANG, Q.; WANG, X.; LIU, Y.; LEE, H.; REN, N. Treatment of biodiesel production wastes with simultaneous electricity generation using a single-chamber microbial fuel cell. Bioresource Technol., v. 102, p. 411-416, 2011.

GNANA KUMAR, G., SATHIYA SARATHI, V.G.; NAHM, K.S. Recent advances and challenges in the anode architecture and their modifications for the applications of microbial fuel cells. Bionsens. Bioelectron., v. 43, p. 461-476, 2013.

GOMES, A.S.; LA ROTTA, C.E.. NITSCHKE, M.; GONZALEZ, E.R. Evaluation of Current Output inPseudomonas Aeruginosa Microbial Fuel Cells Using Glycerol as Susbtrate and Nafion 117 as Proton Exchange Membrane. ECS Trans., v. 41, p. 2011-2017, 2011.

LOGAN, B. Microbial Fuel Cells, John Wiley \& Sons, Inc., 2008.

MOTA, C.J.A.; DA SILVA, C.X.A; GONÇALVES, V.L.C. Gliceroquímica: novos produtos e processos a partir da glicerina de produção de biodiesel. Quim. Nova, v. 32, p. 639-648, 2009.

NIMJE, V.R.; CHEN, C.-Y., CHEN, C.-C.; CHEN, H.-R.; TSENG, M.-J.; JEAN, J.-S.; CHANG, Y.F. Glycerol degradation in single-chamber microbial fuel cells. Bioresource Technol., v. 102, p. 26292634, 2011.

QUEIROZ GUIMARÃES, A.; LINARES, J.J. Glycerol Utilization in Microbial Fuel Cells: Conditioning Stage and Influence of the Glycerol Concentration. J. Electrochem. Soc., v. 161, p. F125-F132, 2014. 
REICHE, A.; KIRKWOOD, K.M. Comparison of Escherichia coli and anaerobic consortia derived from compost as anodic biocatalysts in a glycerol-oxidizing microbial fuel cell. Bioresource Technol., v. 123, p. 318-323, 2012.

SHARMA, Y.; PARNAS, R.; LI, B. Bioenergy production from glycerol in hydrogen producing bioreactors (HPBs) and microbial fuel cells (MFCs). Int. J. Hydrogen Energ., v. 36, p. 3853-3861, 2011.

STANDARD ASTM D1252, Standard Test Methods for Chemical Oxygen Demand (Dichromate Oxygen Demand) of Water.

TCHOBANOGLOUS, G.; BURTON F.L.; DAVID STENSEL H. Wastewater Engineering:Treatment, Disposal and Reuse, Metcalf\&Eddy Inc., p. 11, McGraw-Hill Companies Inc., 2003.

VASCONCELOS, Y. Residuos bienvenidos. Pesquisa FAPESP Edição 196-Junho 2012.

YAZDANI, S.S.; GONZALEZ, R. Anaerobic fermentation of glycerol: a path to economic viability for the biofuels industry. Curr. Opin. Biotech., v. 18, p. 213-219, 2007. 